FAD: A FULL-ACCEPTANCE DETECTOR FOR PHYSICS AT THE SSC J. D. Bjorken

Stanford Linear Acceleratar Center, Stanford, CA 94309

\section{WHAT IS FAD?}

For high energy pp collision,, the concept, "4x" and "full acceptance" are distinel. At the $\mathbf{S S C}$, the appropriate varialles for describing phase spuce are the lego variables: pseudorapidity in and aimuthal angle $\phi$. While most of the is covered by pseudosapidilies bess than 3 of 4 in magnit there is wery interesting physics out to $\mathrm{g}$ 's of 9 wo 12 . For aver a yest ${ }^{2} l$ have been atlempting to encourage an inilialive at the SSC to provide a detector which could cower the missing acceptance of the twa big detectors, which in particular bave to appreciable charged particle tracking with good momentum colution beyond rapidities of 2.5 or 30 .

The gonnegotiable criteria for an FAD are for me the following:

1. All charged particles are seev and their momenta measured we]l, provided pi is got too lerge.

2. All photons are seen and their momenta are measured well.

3. The physics of rapidity-gaps (e.g. inelastic diffaction) is not compro. mised.

Tbis means angular coverage from $90^{\circ}$ dox' n to tens of microradians. The above criteria cannol be met on day one of S5C commissioning with the amount of funds availsble. But l beheve a staged approach is feasible. with a lot of inleresting physics available along the way: We sbail return to practicalities interesting physice

The basit philorophy underlying the FAD ides is thet it should first and fotemost be a survey intlumest, sensitive to almost everything, but optimited for almbost nothing. lts strength is in the perception of complex paltertos in indjvidual event s, used as a signature of new and/or interesting physics. Ex. amples of such patierns will be given later.

The main reason behind $\mathrm{t}$ his philosophy is to proside a delector which has good capability' to sat the unexpected is well as the progranmed, enginetred discoweries (such as $W, Z$, the slandard top quark, or the standard Higgs boson]. There are many examples in the pasl, where the general purpose full. acceplante devices uring advanced technology made important non-engineered distoneries. Three of my favorites are the Berkeley bubble chamber, wich was buill because it gave a superior look at the stracture of tallision: imvolving multiparticle production, even belore there was a clear strategy of that would be leamed. It was responsible Ior the discovery of many hadron resonances, but that was not, I believe, anticipated in advance. Mark I at SPEAR likewise whs the first serions prololype of modern generie is collider detectors, and its discoveries, e.g. quark jets, were again not anticipated in advance. Less spertecular but important to me wat the Piss-Stony Brook full-soceptance defector ${ }^{3}$ at the CERN ISR, which mapped out the fundamenlals of multiparticle production al high energies, using a simple technology (stintillator)

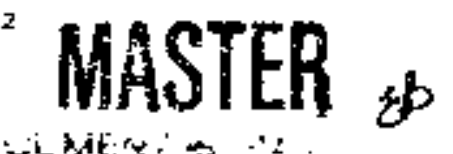


togelher with lulk acceplance. Also importanl for the game reason were the bubble chambers at FNAL and CERS. which for both hadroproduction and acutrino teuctions served a gimilar fole. Al] modern Monte-Carlo programs which underlie to much of modern ideology can be traced back to such exper. iments.

While the present climate is not at conducive to exploratory veot tires as was the case in the past, there are a number of teasons why an FAD aow makes good sense. Among them ate:

1. Physics at targe Feynman $x$ is essentially unexplored at hadron callider energies. It is more than a little arogest to asserl that kearning how the ralence degrees of freedom break aparl in $\Delta$ central collision at extreme energies is nor of interest.

2. The phrsies of tery small $*$, which is also found in the far forward dj. rection for kinematital reasons, is of specific theoretica! interest, becaust pert urbative QCD goes out of control.

3. The phrsics of rapidity saps idifroction) has been largeiv neglected. Large log $s$ is cotential, and the hadron-collider milieu is a gteat oppor. tuaity for advancing our knowledge of this important and diffeult set of processes.

There are Ilso practical reasons for an FAD now, having to do with lechnolog: New technologies ore really what drive scientific adrances. And the most rapidly ehanging highenergy physics technologies are arguably those connected to the informalion industr: data acqujsition, data processing and slorage, and data sndyssis. including pattern-recognilion techniques. In ms: estimates for the FAI prolotype I sketched last year. SWC of the FAD cost was in these lechnologiet.

What has been happening? I began working on this idea in January of 1991. On Apri] I, I made the first presentation of the ides at the SSC, and by May an expression of interest ' ${ }^{\text {' }}$ (ESI- 19 ) was submitted to the SSC Laboralor: This was reviewed by ils program advisory commitiee. which saw enough mesit in the concept to encourage the laboratory to consider the provisjon of the necessary phrgical space far upstream and dowistreary of one of the collision points. so as nol to preclude any sucb initiative. (There was of course no explicit commitmenl to FAD per se.) On December i at SL.4C, the first meeting of the FAD Working Group was held. Since then there have been two more mitetings, one in Dallas and one in Mladison. The idea is that the working group is a collection of interested parties and only that. arganized to explore the phrgics cose and the technical design challenges. By now out memherhip excends 120 . If al goes weil, a collaboration should be formed in about a year from now, with a leadership which is committed to actualiy building the detector, running the experiment, and becoming rich and famous. When the collaboration forms. I would litie to step to the side. remaining a most in "godlather" mode at the pleasure of the collaboration.

The critical-path jtems on our agenda for the coming year are the creation of the delector architect ure. backiground studies. and the detailing of the physics menu addressed by the experiment. While the ordes of importance jo the teverse of that enumerated above. I skrall briefiy d, cribr ithe slated order the status of ous thinking

\section{A. Detector archit ect.12re:}

To see all the collision ptoducts, the detector is essefltially ${ }^{\prime} \cdot .020 \mathrm{Tel}$ hxed-target spectrometers face-lo-face, with a generic ces ltal barel delector linking them. A natural scaling rule is that the length of a brt. arm be propor. tional to the bearn energy: Therefore a rough estimate of the lesugth is given by multiplying the length of a Fermilab I TeV fixed tar1 ril spectrometer by 20. This gives a length of order one kilometer per atm.

There are some differences. In the collidet cage, the cir, ulating beams must go through the cester of the delector, together with an annoying besm-pipe. And the final-focus low' $\beta$ quadrupole magatis are within the detector, serving as and yzing magnets for the leading particles of tahoratory momentum in the multi-TeV range.

This is nat the place or time to go into the details of the detector conceptual design. As of April of this year, the situation is somet hing like what is shown in Fis. 1. The litee space between the low-bet a quads is somewhere around $100+100$ meters: no machine elements are in that region. The machine elements downstream of that free space wibl probably look quite signi]ar to what is Iound in the SSC conceptund degign book ${ }^{3}$ for an intermpdiale- $\beta$ colligion region. We expext a lumisosity around $10^{12} \mathrm{~cm}^{-2} \sec ^{-1}$.

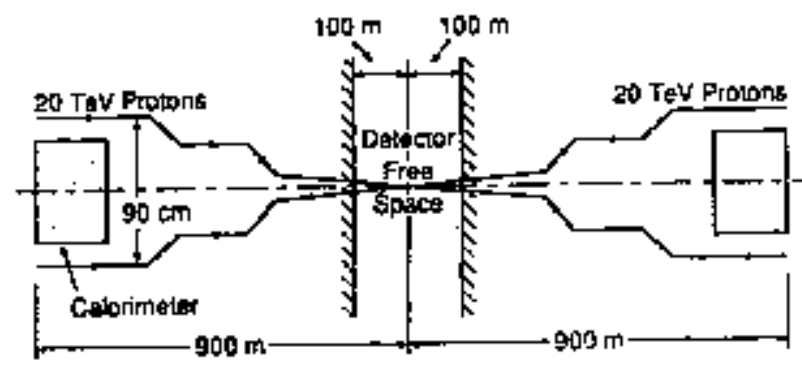

$\rightarrow \rightarrow$

Fizure 1. Sthernatic layout of abe F.AD collision region.

The portion ol the detertor donnetream of 100 meletg mest ste leadirug charged particles and leading pholons and neutrons. Hhile a length of 500 . 1000 meters seems dauntingly large, the actuol siluation is that the detector fiducial volume is in fact rert tral]. Many of the deteclor considerations it. unsterse resolution. multiple scattering, distribution in ps and Fevnman of the leading particless and perhapg eren same of ane boost invaiant 50 one can rien the process in a reterence frame whe is Lorentz contracted by a factor 2000 (Fig. 2), corsesponding to a $10 \mathrm{Ge}$ ? 
prolon colludgrg usth a $40 \mathrm{PeV}$ prolon uth the $30 \mathrm{Get}$ products gosng unto the foruard spectrometer Assuming Fes nmas scaling, it should be eas\} (10 visualize what hind of produets actually go into the teceptance obn jously iers fer per eient, jugt by energ conservation Hibale the transierse space is quile eramped l thus there as probably enough to do the pecessary measurements A worksag subgroup is now bejog organized by John lenulu lo deal with the parameter choscer and detective architect ure in this resion of the phase space

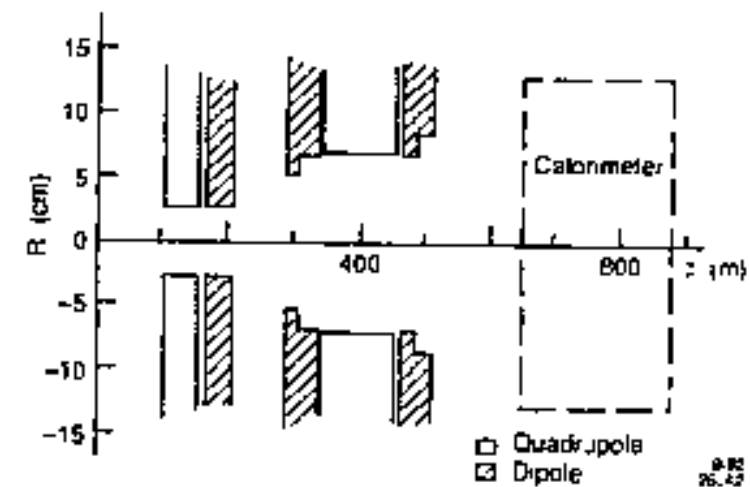

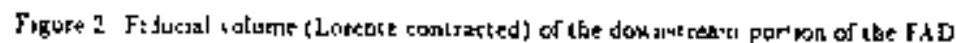

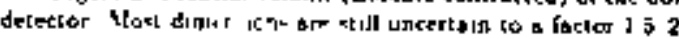

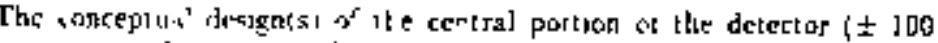

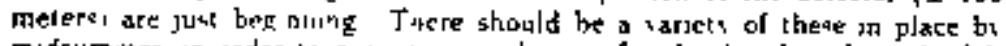

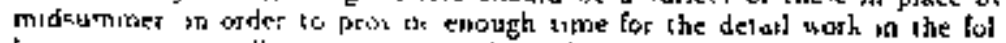

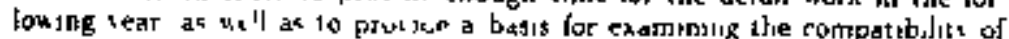

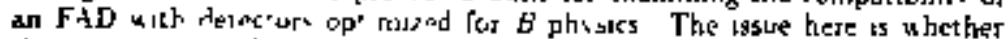

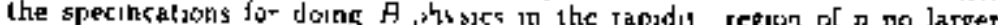

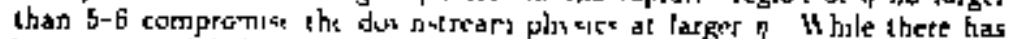

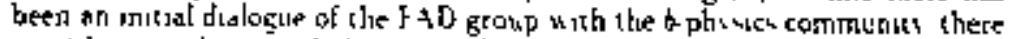

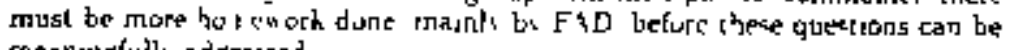
meanumgfuld addresol

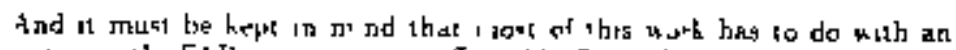

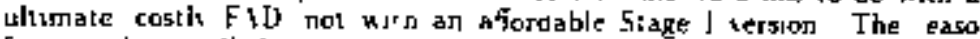
for considesing all th 5 now in 10 sisure arditi sromln polenilal a Stage ]

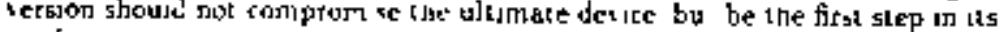
Jmplesmentation

\section{B Backgrounds}

Esen within the \pm 100 meter region of the detector there are dihels to be a number of magnetic stages and for anbular calorimeter ualls The initer

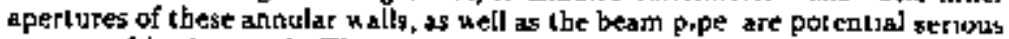
sources of backgraund This passibile bad neu 5 is mulgated bi the fact that beam balo 15 likely to be less of a problem than un am other environment. sirnply because there as no ererg being put jnto the curculaligg beams and because the beam lifetime are long (pronided onls that the machine norks as adiertised') Thus energ conteration alonc therefore prosides a strong argument that halounduced bachgound kill be small On the other hand the background associated with the secondares from the colltsions of nnterest as nell as from bearn gas moterarions are more setious On the basis of hand calculalson estumates, eten these looh manageable Hower es no one will be perauaded of this-including criself-u Jthout a for of torte Carlo simulation

That woin has just begun and much mote ueeda to be done

C Physics

The phrsics menu of a full accprance aehse in definitron vast In the

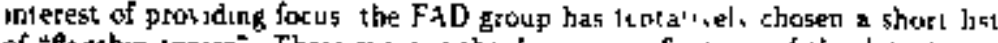

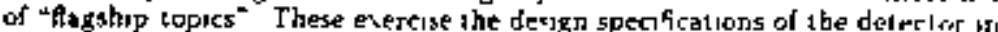

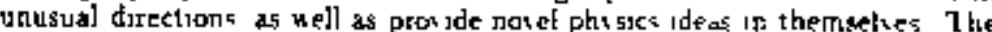
shorl list as of nou, sill rather tentat ie is as follou.

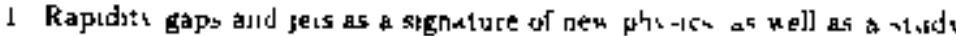
of dufraction a strons untesactions

2 The cosmes sar connectuon leadirg particle jon *

3 Qusth quarh interactuons al fived large $t$ and $\rightarrow$ v these are artost ing to perlurbotice QCD silpposed to get strrig

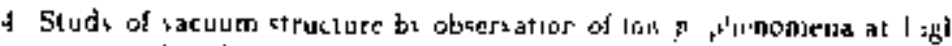
arsocialed mult pluest

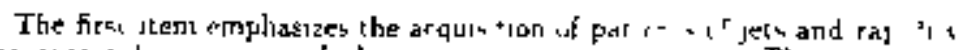

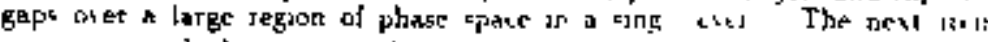

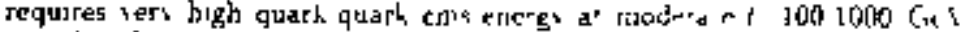

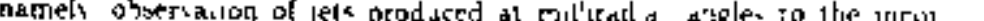
beam These tre found on the 100 are calon nctor wall in front of 15

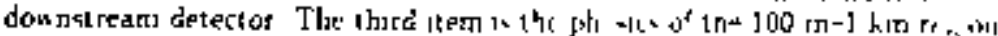

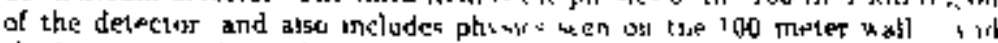

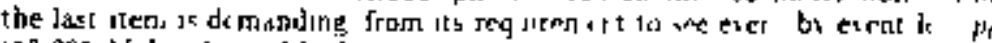

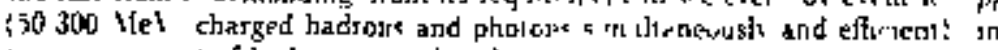

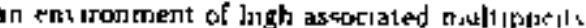

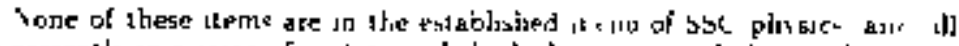

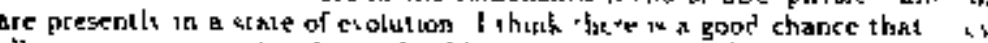

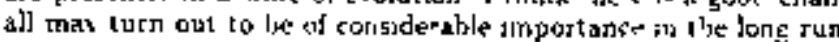

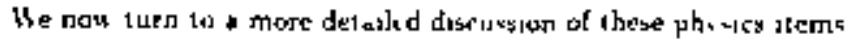




\section{PHS'SICS}

\section{A. Rapidity Gaps and Jet:}

Dufiaction phystes may be defined as the st udy of hadron-hadron collitsons

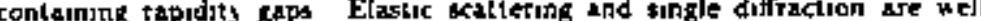
sludned, althour b much remans to be done on double.difraction and bes and In addition, there art only the beginnings of experinental st vdies of proceases contsising both rapudity-gaps and jets ${ }^{5}$

A vern unteresting set of processes contarning both rapidity-gaps and jets are those induced by electromeal-boson exchange ${ }^{6}$ This uncludes productson of the Higgs bosan by $\mathrm{H}^{-}-1 f^{-}$flusion This process has been discussed in some detayl ${ }^{\prime}$ eluewbere, and ue will not repeat that discussion bere Sulfice it to sey that the pattern shown in $F_{\mathrm{Jg}}$ 3. whicb lestemate lo occur un a lew percent of all Higks production erents. Is a rery strong sigature, arguably backgroundlee The essential feature of the signature is the abs. ice of an underlyog crent only the products of the Higgs decax appear w Il hin the acceplance of a genterie 45 detector Eien a Stage I F $4 D$ 'tol deteclor, duscussed in Section could arcuabli acquire and usolate this clast of everis

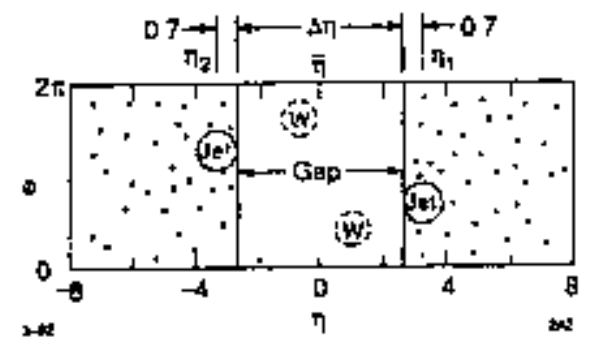

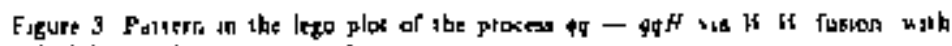
curvinat of the rag dirs ge - enmed

There are mas; QCD issues ralsed bi the consideralion of the atove strat-

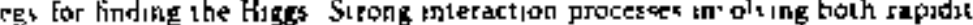

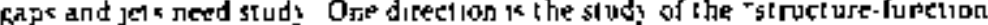

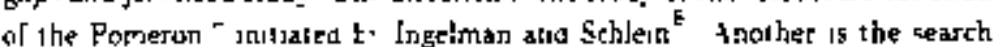

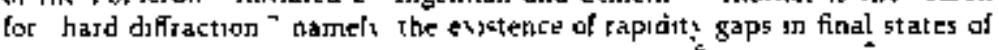

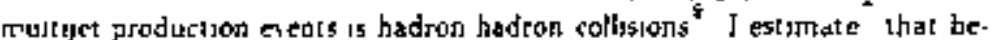
tween $10^{-1}$ and $10^{-3}$ of al] generic coplanar QCD ino jet esent5 us ll contaln

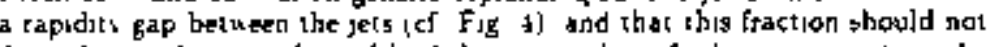
oepend atrongly upon the uadth of the gnp lat lezst for large gaps, where the rapsditi difference of the final ztate jer us largel nor upon the pi of the jets Thus should not be hatd to test expersmentalls rued uth the 4 T detectors of limited rapidit\}-arceptance $x$ bich now exigt The generalyzalions to multulel and/or multsgep processes are also clearly of considerable 1 torest be a sery 4pproprinte physcs menu for \& FAD, eben in Jts Stage I juecrnation Werk on this is in progress 10

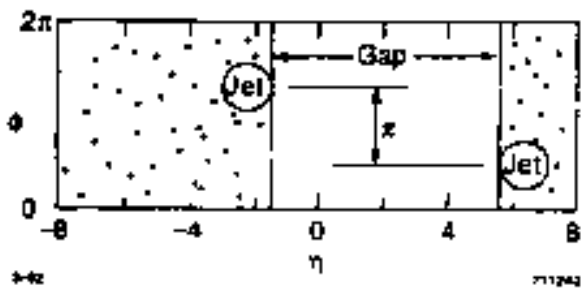

Figure 1 Erent structure for hatd double difirwethua The process a th th gap mas be?

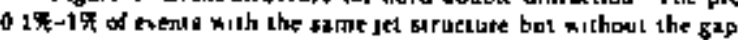

B. Quark-Quark interactions at fixed latge $t$ and very I qrge \&

It is expected from perturbatuve QCD that, even at short distapces, the parton parion intefartuon gels strong al extremely Jajge cms encrgies This largers problem. usually called the smalk. I problem ${ }^{\text {lif }}$, occurg because the perturbature single-g]uon exthange is enhaneed by mulu gluon emussion, as described by the BFhI evolution equation ${ }^{27}$ Yveller and Varelet ${ }^{13}$ hate proposed two expenments ubich test this tdes snd which uould explore the

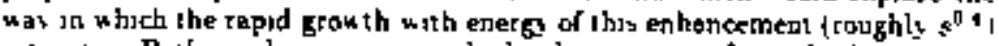
balurateg Both imolie measuring the hard seatlenag of sar, leadung quarha with $x \geq 01$ One obseries the secondary quarbs in 1 h h $p_{1}$. 5ay. of $50.30 \mathrm{Get}$ The cross section con!d be enhanced re]atse to nane one gluas exchange Li two or mose orders of magntude Because of the multughon enssyon the coplanatly? of these tho jets is expected to be washed our Honeter there hould also be a 2 gluon. colos-singlet ladder exchange it he -hard Pomeron I of comparable magnitude ptesent This is the parton level analogue of elastic

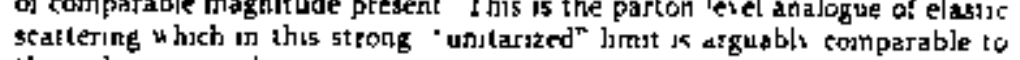
the inelastie cont roution

The 1 pical production angles of these kuetter Yarelet jets ate of order molliradians Thus the jet cortes a $e$ onl avss when thes strshe the IMV th calorsmeter ualf Tnus should be quite ob seriabte tn the FiD although it does put strong dernands on the quafity and

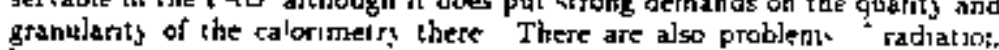
hardness and good angulet resolution wheh must be addressed

Sted of the multiple production of jels which underlyes the viuelter satelel-BFhL phisict is of comparable importance The [u] accepiante of FAD is clearely of grest ralue lor such studies ${ }^{\text {to }}$ 


\section{The cosmic-ray connection}

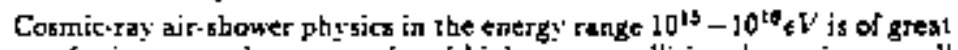
interest for it 5 as n sake as a probe of high-energy collision dytamios as well as for its astroph'sical implications; the origins of such high-energy primaries are not understond.

An important ingredient in unfaveling this physics is good understanding of the air-shower dynamies. especialty in the esply stages of esolution, where the ieading particie physics (Feyman I greater than 0.01) predominat es. This region is essentialty unexplored at contemporary hadron-coltider energies. In the FAD detector. it corresponds to the phissics at the $100 \mathrm{~m}$ endursll and dornstream of it.

There has been dificuly' in accouding for the properties of air shoxerg, as wel] as of individiual events. assuming a oomenalog: upward in energy. This is truc even after taking into account the oomeadog: upwasd in energy. This is truc even after taking into account the And these remain the puzzling Centaujo/Chiton , ent classes to explajn as well ${ }^{14}$. A possibie explanation. howerer. is suggester in the next subsection.

\section{Disoriented chiral condensate and racuum structure}

Collisions with very high astociated muthiplicity produce "fireballs" which expand radialty. from a he collisian point ar the speed of light. and which probably persist to a relatjuely lasge hadrooization tadus $R$. defined as thal radius wibere the final-state pioms are created ac idenifiable hadrons. Ylost of the energy and ent ropy of guch a frebatt or guably is found nenr its surface learing energy sand ent ropy of such a frebal orguably is loond Denr its surface learing a tejarjely cool interior. This jeterior tegion may be of special interest. Because of the approxinale chiral stimenetry of the strong ineractions, the jnerigr region may relax to a state in which the otientation of the chicat

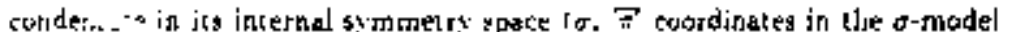
descriptionj is not in the $\sigma$.ridection. but displace tound one of the $\pi$ difec. io:ts. The usual cost in surface energ existing in more gentle urtcurastances witl here be negligible because of the large curface energr density of the fireball which iscolates this discriented yacuun from the true exteris iselsum.

The disujented zacusm can sarrive only until the fir thsil-s]ell hadronizes.

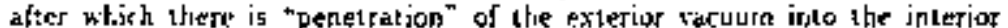
solume. During this prened the classical fireld describise the dilference of the disoriented aud mormal racus will to fadisied axay. This is esseritially a

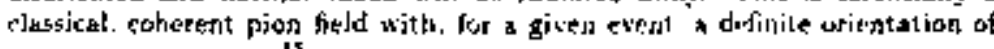
its [carleciand isospin 15

Some serni-quantilative studies of the salure of such rehu:lent fadiation hive alseady been carried oul 16 . In addition there ape in the literature some clresely related studies". Because of the colyesente of the wurce. this mecha oism provides a candidate interpretatiun of Cenlaurs cusnic-ra\} vients (1arge Hisctuations in the neutral-to-charged parlit le tatiosj as wetl as the Chiron

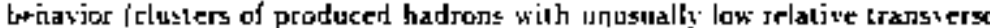

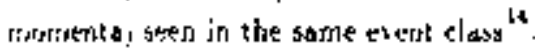

A greal deal of theoretical work can be done. Some is in progress. 1 hope that, at the least, working popers if not journal publjeations on ihis ptrysics. as wei] as details of the experimental search strategies (including simulations). will be produced by the FAD working Group in the next half-yess.

\section{E. Other physics}

Sinch physict of special intereat and appropriateness to a [ul] acceplance detector such as FAD has been omitled in the physics "short-list," One nuay creale sery long lists of topics, which could form the table of contends ior a conference on multiparticle production. Whithout going that far. we only mention a lew other subjects where we expect active interest from oshers in the community;

One is heavy-favor physics, not only boltom physics, bul also charm physics. In both cases a god for design of the ull imale Stagc- $N$ fult-acceptance detector should be that this can be done with the highest stanclards of quality detranded by that community.

Another is the problers of physics of soft and semihard multiple production: minijets, multiplicity correlations, internittency. elc." Closely relaled is the issue of whelber quark-gluon plasma is produced in high-muitiplieity etents.

Yel another is tolal and elastic-cross section measurements for nuesoumeson and meson-bargon collisions. using leading particle tags to jmolale ons'meson exchange cont ributiposs ${ }^{19}$. Fir example. the $x^{-} \pi^{-}$inleraction can be siudied vis obser'ing two learfing $\mathbf{3}^{++}$baryolus.

The precess

$$
p p \rightarrow 3^{++}+x^{++}+x
$$

can be extrapolated (Fig. 5) 10

$$
\vec{n}^{-} \mathbf{x}^{-} \rightarrow \mathbf{H}^{-}
$$

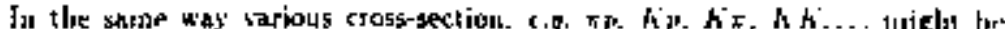

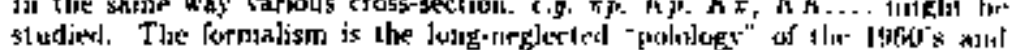
1ripla-liegse tormalism of tise carly $1970^{\prime} \mathrm{x}$.

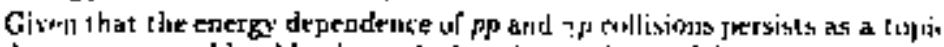

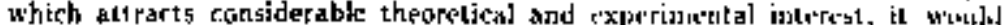

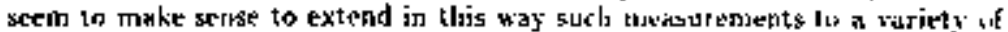
ot lier projuctiles.

\section{Fl:TLHE IDANS OF TIE FAD WOKLIXU GROAL}

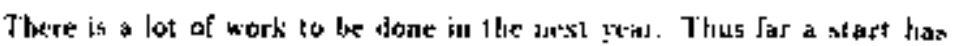

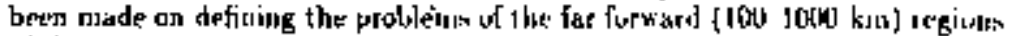

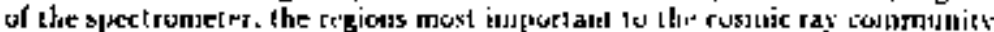

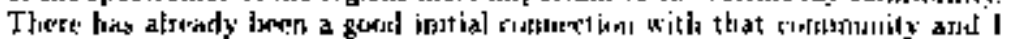
hope this witl ecousinue to grom in the futurr. 


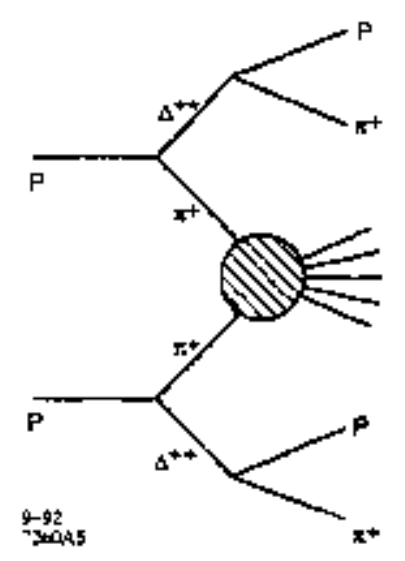

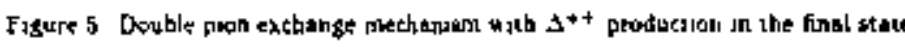

In general [ would like to see convderable bottoms up thinhing on the architertural problerns of this detector I see thes proceeding in siagrs, the first of $u$ hich is lo define the cslonmetre acchutecl ure Bachground studics aाt serr tssential in detertinning the amoulat of freedom of charce there is at this stise Thercalier, the traching arcbiteciure (kithout magnetic fields) might be the next ratural slep to be considered uith the maeneluc arehitecture consideted

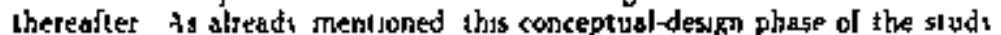
which is in here mari, cholces of Jollg rarige importance w ill be made, should be

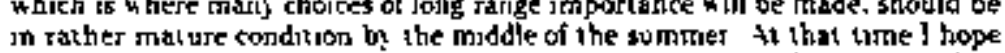
there $w$ il] be a sartet of conceptual designg on the table, which car for a while be developed in parallel bn therr tunds proponents Such design competituon will be aluable in hardening the arguments for the ulkmate desagn chouce riade at proposal time

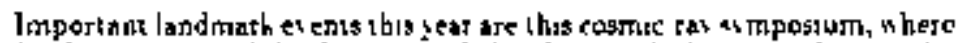
the far fornard part of the detectar and the physicg whek goes with it can be further considered and the Rochy Hountan Consortum metsings in Boulder during the mosth of Juls Thes metrings are the one opportunits for an "FAD Snoumass ${ }^{-}$before proposal uriting tume romes along $B$ the end of July a da alogue with the b-phrgies community ought to be jujtiated. so that by the fall, when there is a $b$-phisjcs norkshop al the SSC, there can be meanngiul consudetalion it the compatibulus and integrabuluty of hrais flator

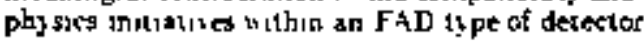

Essential as the practical questuon of uhat defines $+S t a g e$ I FAD to ob vaus eriterion je cost fl the December meting ue tentatisely chose a alue

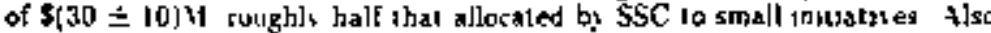
thers $u$ as a len1guice consensus that enen at this shage one try to adhere to the full arceptance plulosophis wh o reasonabis uniform distrbution in vestment as function of 7 Since that time there has beer. some considci atuon of whether auch a stralegs 15 practical This has led 10 a sersion of Siage which might be called a tor telectof

The furnction of the 10, detector is to acquire the coarse graned paltern of indindual events The lego plor is dis sded up into coarse pineis of area $07 \%$ $0 i$, sas This amounts ta about 200 in the full delector, excluding the special far formard regions The anly information per puxel dernanded is the charged multiplicity and the electromagnetic pa, wh hadronic $p_{1}$ and isolated muons added in if it is affordable Aequiring thes 1 information can be achieved with as elaboration of Pisa-Stony Brooh ${ }^{2}$ with essentially 1950's technology a mosase of scintillator telegcopes, one for each pixel With 20 panels of scintillatos per pixel, and even an undisidual photomultipher for each pane], this adds up to at most 4000 channels on insextment uhjeh mas fit whthon the $\$$ tagc I budget Such o dessce standing alone could do a considerable amount of expotalory rapidity-gap-plus-jel phisics including arguably the obsertation at the SSC of the TeV higgs discussed in the previous section ${ }^{\prime}$ find an R\&D program w ith protots pe iersions of the tot in FN $\&$ L fixed target beams *5 wetl as possibl FNAL andfor FHIC colluding beams could prousde an orderls patbuar bet ect now and SSC commssioning for tegting the delection strategr. as a cll as for advancing the expertmenlal status of goit semihard and hard diffraction processeg

In conclugion I thinh the FAD represents a rather neu detector concept * tuch requites botiotis up thinhung in almost all its asperts The nevt vea should be filled usth thinking more about fundamentais of detector design and uarous novel phistes topers and less about moner and poluturs

If FAD indeed succeeds I thish ansone tnolied wall remember this expr rence witb the gresiest of oleasure Thus hind of opportunit dors not of ten occur

\section{Acknowitedgennents}

Vian members of the F \&D working group, loo numasous io enumetale here have made and are unahing exsenlual contributuors 10 this effort and ut ts a pleasure to achnow ledge that here [ also u, ish to ach riow] dedge the unporient suppott and eveouragement of the 55C Laborators 


\section{REFERENCES}

1. J. Bjorken. Int. J. Mad. Phy̧s. AJ, 18, 4389 (1992).

2. L. Fon, Phys. Repts. 20C 1 (19i5).

3. SSC Sit-Specific Conceptual Design; SSCLSR-1056 (I990).

4. A. Weidemonn, G. Gretnbaum, N. Mokhov, private comrnupication.

5. See A. Brandt, Nud. Pbys. B (Proc. Suph.) 258, 26 (1992) and refertaces twerein.

6. Y. Dokshitzer, V, Khoze, and S. Troyan, Protiedizgs of the Sizth intemational Confertect on Physics in Collitions (1986), ed. M1. Derrick [World Scientific, Singapore, 1985 ], 365.

7. J. Bjorken, SLAC preprint SlaC-PUB-5616 (1992).

B. G. Ingelman and P. Schlein, Phys. Lett. B152, 256 (1985).

9. H. Chebine th al., Phys. Lett. B286, 397 [1992).

10. V. Del Duea, prisate communicalion.

11. For a review see E. Levin, DESY prej-int DESY 91.110 \{1991),

12. E Kinraet, L. Lipalor, and V. Fadin, Sor. Phys. JETP 45, I99 (197i).

13. A. Muelies and H. Navelet, Niucl. Phỵg. B282, 272 (1987).

14. S. Hasegara, these proceedings.

15. Some discussion can be found is J. Bjorken, SLAC-PLE-j6i3 and reference 1 .

16. J. Bjorken and 31. Heinstein (unpublished); K. Kox-alski and C. Taylor [privgte communication).

17. A. Anselm and A1. Ryskin, Phys. Letl. B266- 482 (1991): J.-P. Blaizo! and A. Kizyłxicki, Phžs. Rer. D46. 246 (1992).

13. For a review, see W. Kittel and R. Perchanski, Nucl. Phss. A582. 489c [1991] and references therein.

19. W'. W'alker. private comnunaication. 

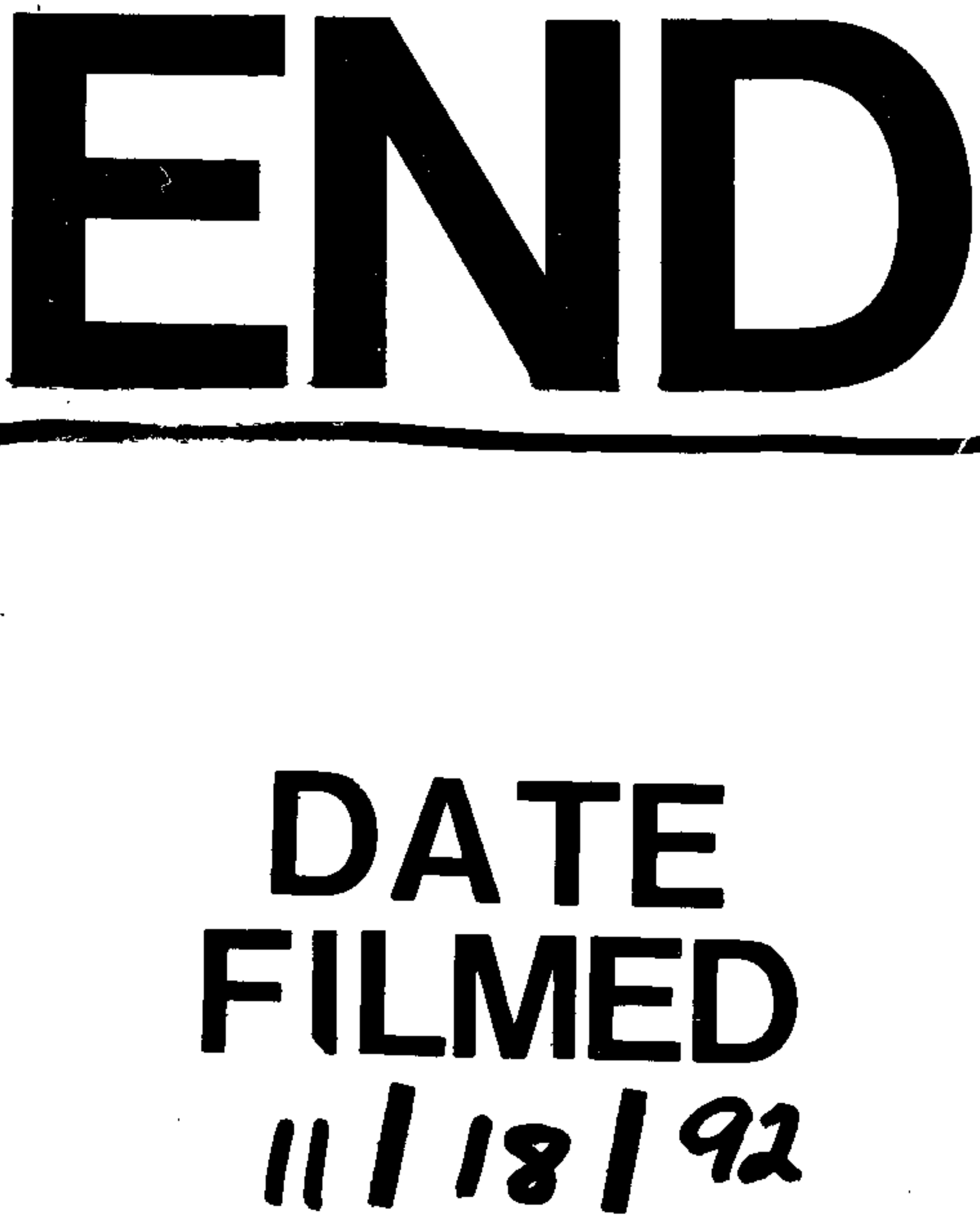
